\title{
ОТРАСЛЕВОЙ РЫНОК УСЛУГ: ОСНОВНЫЕ НАПРАВЛЕНИЯ ИССЛЕДОВАНИЯ И РЕГУЛИРОВАНИЯ
}

\author{
(c) 2020 Попова Елена Александровна \\ доктор экономических наук, доцент \\ Южно-Уральский государственный университет \\ (Национальный Исследовательский Университет), Россия, Челябинск \\ E-mail: 73519045153@yandex.ru \\ (c) 2020 Демина Надежда Константиновна \\ кандидат экономических наук \\ Южно-Уральский государственный университет \\ (Национальный Исследовательский Университет), Россия, Челябинск \\ E-mail:deminank@susu.ru
}

Обоснована базовая модель парадигмы формирования отраслевого рынка. Показано его место в структуре внешней среды хозяйствующего субъекта. Основное внимание уделено механизмам регулирования отраслевого рынка с позиций эволюционной теории его инновационного развития.

Ключевые слова: отрасль, рынок, модель, спрос, предложение, инновационное развитие, эволюционная теория, спорт, физическая культура.

Введение. В последние годы в нашей стране имеет место повышенный интерес к проблемам формирования и эффективного функционирования отраслевых рыночных структур. Отмеченное обусловливает необходимость комплексного всестороннего изучения связей между отдельными организациями внутри отраслевых структур, между структурой рынка и его результативностью. Проведение данных исследований в этой области позволяет решать целый ряд проблем, направленных на рационализацию структуры отраслевой экономики и выбор стратегических направлений ее развития. Речь прежде всего может идти об адекватной оценке внешней среды, выявлении и распределении сил в конкурентной борьбе и выработка основных направлений по созданию и развитию конкурентных преимуществ. В рамках нашего исследования к числу актуальных относятся также вопросы комплексного подхода к анализу предложения и спроса на рынке услуг, классификации и структуризации отраслевого рынка, организационного культуростроения в системе «рынок - физкультурно-адаптивная организация (ФАО)», оценки возможностей регулирования и инновационного развития отраслевого рынка сферы адаптивной физической культуры.

Степень исследования. Интерес к вопросам организации рынка, его монополизациии, наличия сговора впервые появляется еще в трудах

Аристотеля и А. Смита. Однако, как обособившаяся экономическая наука, теория организации отраслевых рынков возникает значительно позднее. Впервые термин «организация отраслевого рынка» появляется в трудах А. Маршалла [4] в 1879 г. Именно в этот период в экономических научных кругах возникает повышенный интерес к участившимся случаям проявления рыночной власти и неопределенности ее последствий. В то же время основной акцент в изучении рыночных структур того времени делается на проблему изучения монополий (трестов) и промышленной политики государства в отношении этих структур.

В мировой экономической науке существуют два подхода (парадигмы) к изучению отраслевой организации экономики. Первый - Гарвардский. Согласно ему существуют определенные условия, в частности, технология, наличие спроса, масштабы производства, определяющие структуру рынка. Второй - Чикагский. В его рамках исследуется теория цен и рассматриваются закономерности принятия оптимизационных решений в сфере взаимоотношений производителей и потребителей физкультурно-адаптивных услуг.

В настоящее время наблюдается сближение этих подходов к изучению отраслевых рынков. Это выражается в расширении спектра применяемых инструментов экономического анализа: 
эконометрические модели и механизмы регулирования, ситуационный анализ, проведение экономических экспериментов, что позволяет более глубоко и детально исследовать отраслевые рынки.

В общем виде современная теория организации рассматривает сферу несовершенной конкуренции в части поведения ее участников, возможного исхода их взаимодействия, а также влияния на общественное благосостояние и границы правительственного вмешательства. Сфера исследований, которая нас прежде всего и интересует, определяется: возможностью приобретения рыночной власти, ценовым соперничеством, антимонопольной политикой, стимулированием нововведений, конкурентоспособности физкультурно-адаптивных организаций, их организацией и поведением на рынке услуг, подверженных регулированию со стороны региональных и государственных учреждений власти.

Результаты исследования. В концентрированном виде они выражены в виде схемы, приведенной на рисунке 1. Прежде всего они представлены в цепочке связей: основные факторы внешней среды - ФАО - предложение услуг отраслевой рынок - спрос на услуги. Кроме того, есть еще одна цепочка, определяемая ключевыми экономическими характеристиками отрасли и составляющими ее развития.

Назовем основные признаки отраслевого рынка сферы адаптивной физической культуры (АФК), а именно: механизм сведения воедино покупателей и продавцов, конкуренция, обмен, цена-посредник, финансовый бюджет, риски участников, институт сделок и коммуникаций, системность отношений. Есть и другие признаки, называемые разными исследователями (отечественными и зарубежными).

Остановимся далее на типах отраслевого рынка. Нами выделено десять их классификационных признаков, отличающихся по:

- объекту и субъекту сделки,

- наличию посредников,

- времени подачи прав собственности на объект сделки,

- формам собственности,

- точки зрения рыночного законодательства,

- характеру продаж,

- степени наличия конкуренции,

- условиям реализации услуг,

- степени фокусирования на потребителе (по сегменту),

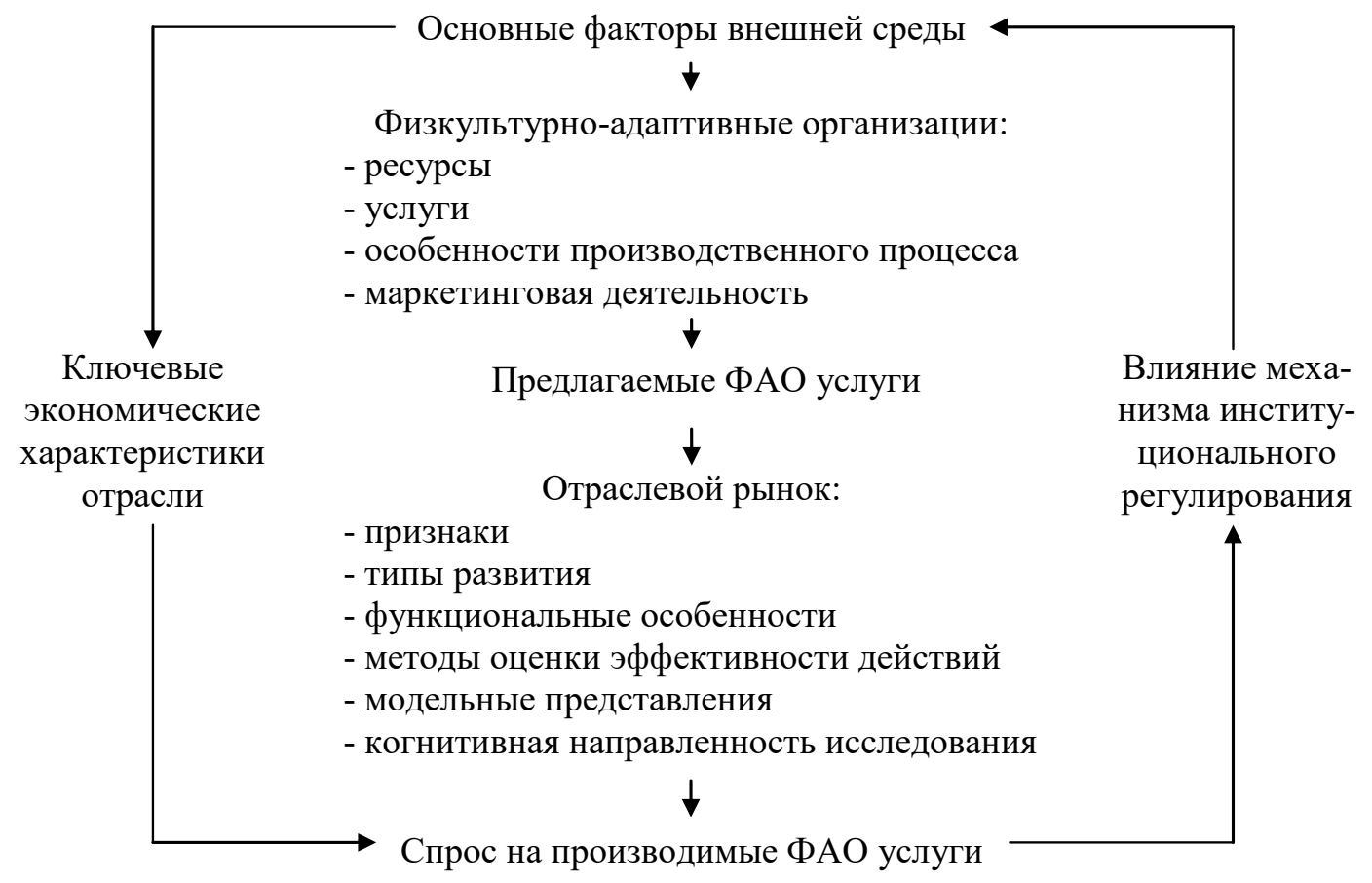

Рисунок 1. Отраслевой рынок в структуре внешней среды физкультурно-адаптивной организации ФАО 
- пространственному размещению (географии сделки). Конкретно речь идет об определении границ отраслевого рынка сферы АФК. Эти границы следующие: потребители услуг, организационная культура, а также временные, продуктовые и локальные границы.

Для сферы АФК важно когнитивное представление отраслевого рынка [9]. Некоторые авторы речь ведут о когнитивном походе к направленности нашего исследования, к преимуществам которого можно отнести возможность: использовать разные методы и модели, объективизировать знания специалистов в предметной области, формализовать изучаемую проблему, прогнозировать результаты управленческих воздействий, принимать рациональные решения в условиях быстрой изменчивости внешней среды.

Особую роль при этом играет институт доверия и экономическая власть (рисунок 2). Последняя, в отличии от политической власти, распространяется только на материальные ресурсы и гарантируется правом собственности на них. И чем более дистанцируются эти виды власти друг от друга, тем универсальнее является природа согласия, а следовательно и ниже трансакционные издержки физкультурно-адаптивной деятельности.

Особое внимание институционалистами обращается на конституцию отраслевого рынка (ОР). Алгоритм исследования отраслевого рынка при этом можно представить следующим образом (рисунок 3). Такого рода исследование необходимо для обеспечения эффективного функционирования национальной экономики и удовлетворения потребностей населения региона. Эффективная система отраслевых рынков, обслуживающая хозяйствующие субъекты, повышает их деловую активность, способствует нормальному воспроизводственному процессу в регионах России.

Отраслевой рынок представляет собой территориальную организацию сферы обращения, где происходит согласование интересов производителей и потребителей» [6]. Он имеет открытый характер и развитие связи с другими регионами страны.

Рынки объединяют в единое целое внешнее и внутреннее экономическое пространство регионального воспроизводственного процесса, а внутреннее пространство является социально - экономической средой для формирования инфраструктуры системы этих рынков. Внутреннее экономическое пространство включает условия и предпосылки для функционирования любого отраслевого рынка, а внешнее выступает потенциальной средой реализации услуг, гарантируя возможность участия всех субъектов в рыночных отношениях как равноправных партнеров, соблюдающих нормы и правила рыночных отношений [12].

Основные - рыночные - теории названы в таблице 1. Их можно подразделить на теории:

- размещения производства и среды обра-

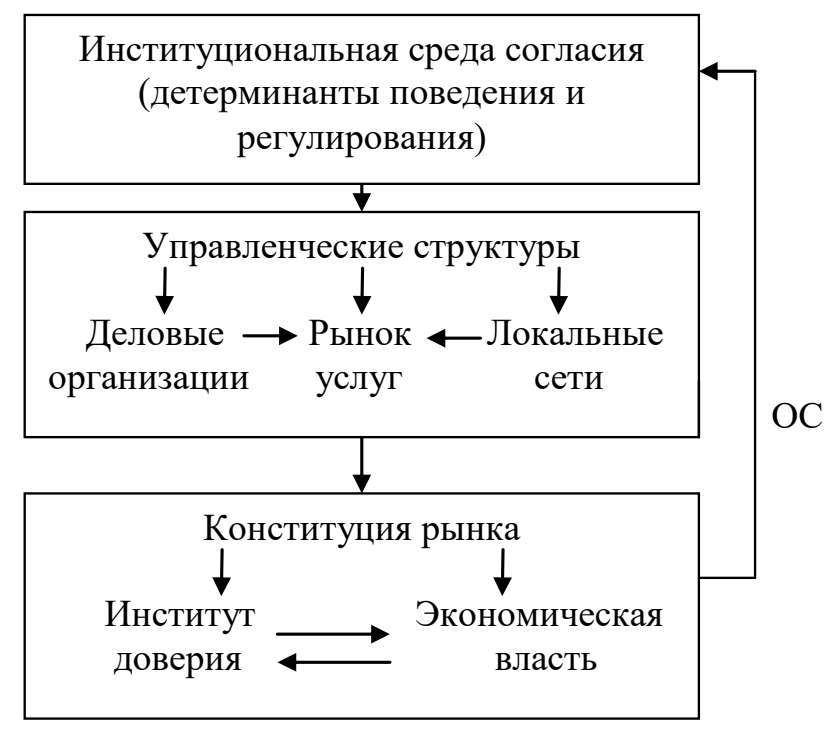

Рисунок 2. Когнитивное представление параметров конституции отраслевого рынка: OC - обратная связь, определенная нормами и правилами экономического поведения его субъектов 


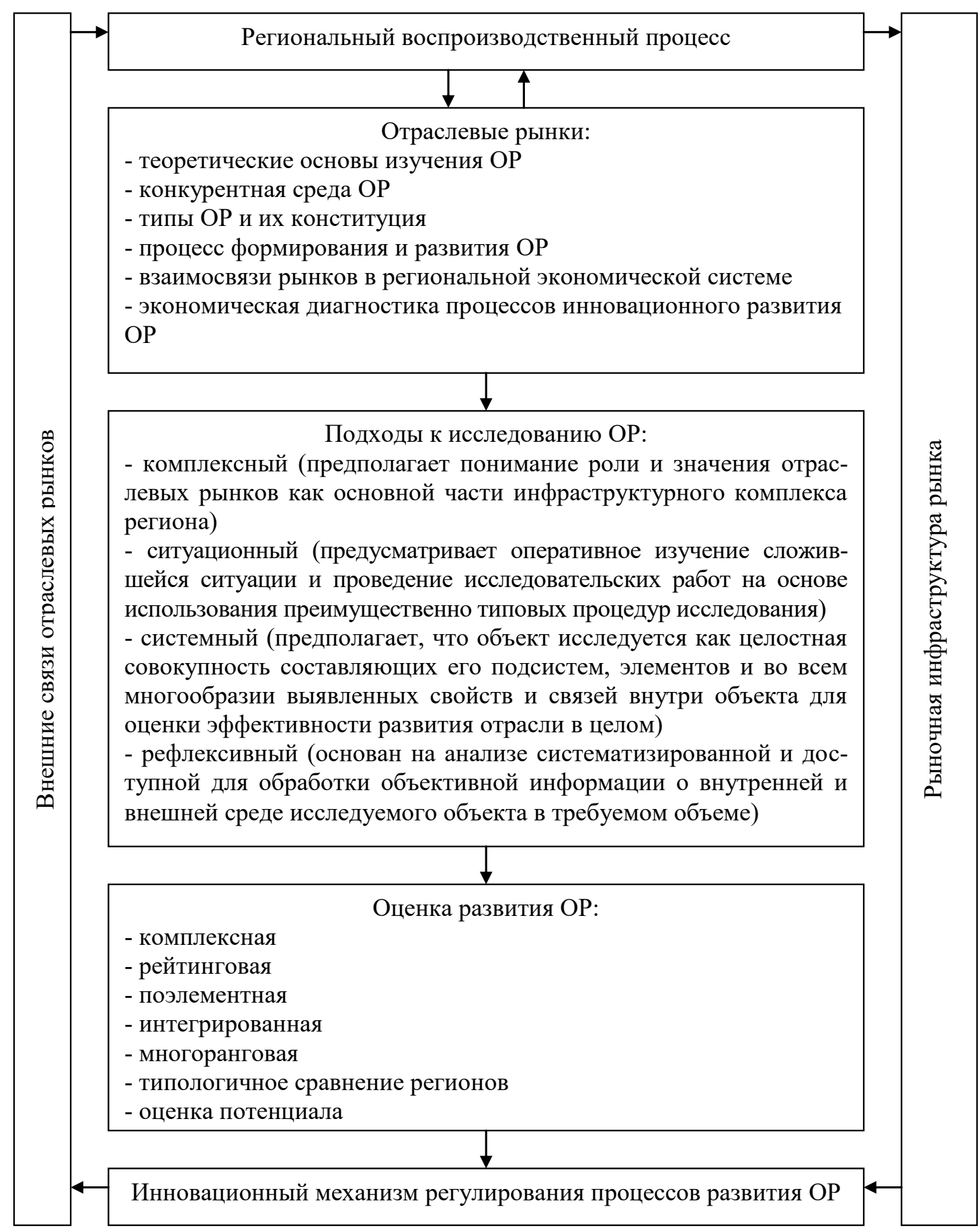

Рисунок 3. Алгоритм исследования отраслевых рынков (OP)

щения;

- рыночных потенциалов и пространственного взаимодействия;

- центральных мест;

- геомаркетинга;

- пространственного распределения потоков физкультурно-адаптивных услуг;

- институционального подхода к анализу рыночных процессов.

В последнем случае речь идет о работах Р. Бреера, Е. Дудди, Д. Ревзана. Они (в свое время) предложили комплексную институциональную структуру рынка, включающую различные типы экономических агентов: предлагающих услуги финансирования и кредитования, посредничества в сфере рекламы, страхования и 
др. Дж. Энсминстер трактует рынок как систему институтов, которые необходимо создавать в развивающихся странах для ускорения темпов роста всей экономики. Отмеченное - во многом - относится и к отраслевым рынкам физкультурно-адаптивных услуг.

Можно констатировать, что отраслевые рынки выполняют ряд функций в региональной и национальной экономике. Путем обмена они обеспечивают - как справедливо утверждают специалисты - непрерывность воспроизводства материальных, финансовых, информационных ресурсов, а также трудовых ресурсов - человеческого капитала.

Основные направления комплексного исследования отраслевого рынка следующие: анализ конкурентной среды и рыночной инфраструктуры, анализ конкурентной среды ОР, экономическая диагностика процессов развития ОР, выявление взаимосвязей рынка в региональной экономической системе, изучение форм и методов регулирования процессов развития ОР.

Последнее направление рассмотрим более подробно. С этой целью будет использована работа «Государство и экономика» [11], а также другие результаты исследований отечественных и зарубежных экономистов.

Государство - это институт, воплощающий общую волю, общий интерес составляющих его граждан. Главная задача государства состоит в обеспечении порядка в стране, неукоснительного соблюдения всеми гражданами законов данной страны. С этой целью оно использует все находящиеся в его распоряжении средства, в том числе и физическое принуждение. Для демократического общества характерна система разделения высшей государственной власти на три самостоятельные ветви - законодательную, исполнительную и судебную. Во взаимной борьбе и органическом взаимодействии они обеспечивают такую систему противовесов, которая не позволяет ни одной из них занимать господствующее положение. Главными аспектами деятельности государства является не столько сбор и распределение бюджетных средств, сколько конкретные мероприятия и программы, осуществляемые на эти средства, и результативность государственного контроля над их реализацией [8]. В последнем случае речь идет об институциональном регулировании процессов развития отраслевых рынков (ИРОР), и прежде всего обеспечении нормального функционирования рыночных процессов на региональном уровне.

Ключевое место в ИРОР занимает государственно-административный аппарат. Его деятельность направлена на «упорядочение развития в интересах всего общества» (Р. Грегуар).

Таблица 1. Основные - рыночные теории

\begin{tabular}{|l|l|}
\hline \multicolumn{1}{|c|}{ Автор } & \multicolumn{1}{c|}{ Суть теории } \\
\hline 1. Д. Уэлд & $\begin{array}{l}\text { Предложил различные варианты рационализации системы движения товаров и услуг, } \\
\text { которые могли бы облегчить их реализацию }\end{array}$ \\
\hline 2. О. Энглендер & $\begin{array}{l}\text { Обосновал целесообразность размещения производства вокруг рынка - потребитель- } \\
\text { ского центра товаров и услуг }\end{array}$ \\
\hline 3. Т. Паландер & $\begin{array}{l}\text { Ввел понятие «линейного рынка», под которым понимал рынок с равномерным разме- } \\
\text { щением потребителей по территории и с одинаковым неизменным спросом на товары } \\
\text { или услуги }\end{array}$ \\
\hline 4. А. Лещ & $\begin{array}{l}\text { Рынок является главным районообразующим фактором и результатом борьбы различ- } \\
\text { ных экономических сил: одни силы способствуют тенденции к концентрации, другие - } \\
\text { к рассредоточению }\end{array}$ \\
\hline 5. У. Изард & $\begin{array}{l}\text { Изучение рынка в его пространственном аспекте выдвигается на первый план и высту- } \\
\text { пает в качестве главного фактора, определяющего развитие и размещение производ- } \\
\text { ства товаров или услуг }\end{array}$ \\
\hline 6. Х. Бос & $\begin{array}{l}\text { Показал, что для практических целей можно приближенно определить оптимальную } \\
\text { рыночную зону как круг }\end{array}$ \\
\hline 7. Я. Гамильтон & $\begin{array}{l}\text { Рассматривает «слои» иерархической системы хозяйства как рыночные зоны для про- } \\
\text { мышленности в целом, или отдельных отраслей }\end{array}$ \\
\hline 8. А. Шсффле & Сформулировал схему гравитационной модели \\
\hline 9. Д. Рэй & $\begin{array}{l}\text { Предложил расширенный вариант модели пространственного взаимодействия рыноч- } \\
\text { ных потенциалов с учетом влияния финансового капитала }\end{array}$ \\
\hline 10. Р. Бреер & $\begin{array}{l}\text { Подразделил рынок на первичный и промежуточный, организованный и неорганизо- } \\
\text { ванный, а также основных агентов рынка }\end{array}$ \\
\hline
\end{tabular}


Государственный чиновник в этом аппарате выступает специальным агентом власти.

Содержательной частью государственноадминистративного аппарата (ГАА) является исполнительная вертикаль, представленная Администрацией Президента РФ [3]. Благодаря её наличию осуществляется планирование, учет и регулирование процессов развития ОР (рисунок 4).

С точки зрения эффективности системы государственно - административного управления не маловажное значение имеет механизм принятия решений, имеющий результатом выбор из социально определённого, ограниченного количества проблематичных альтернативных планов одного из них.

На характер и определённость принимающих решений значительное влияние оказывает как существование многих органов, которые нередко дублируют друг друга, так и разделение властей, которые обладают возможностями наложить вето на решения друг друга [1]. Возрастает также сложность и объём правового регулирования деятельности органов государственно-административного управления.
С этой точки зрения интерес представляют принципы выбора при принятии институциональных решений в сфере регулирования OP: беспристрастность; индивидуальность; непрерывность; максимизация, а также справедливое распределение благ, обеспечивающее удовлетворение интересов большинства членов общества; автономность, которая предполагает определенную степень самостоятельности органов, принимающих решения; безотлагательность, означающая оперативное и своевременное принятие и реализацию необходимых решений.

В теории государственного регулирования известно два направления: классическая школа и школа человеческих отношений. Обе они, по-своему, дополняют друг друга. Представителей первой школы объединяет убеждение в том, что система государственно-административного управления должна быть ориентирована на достижение поставленных целей с максимальной эффективностью при минимальных затратах.

При всех достоинствах данной школы важным ее недостатком является тот факт, что конструкции ее представителей не совсем обоснованы, когда речь идет об использовании в полной

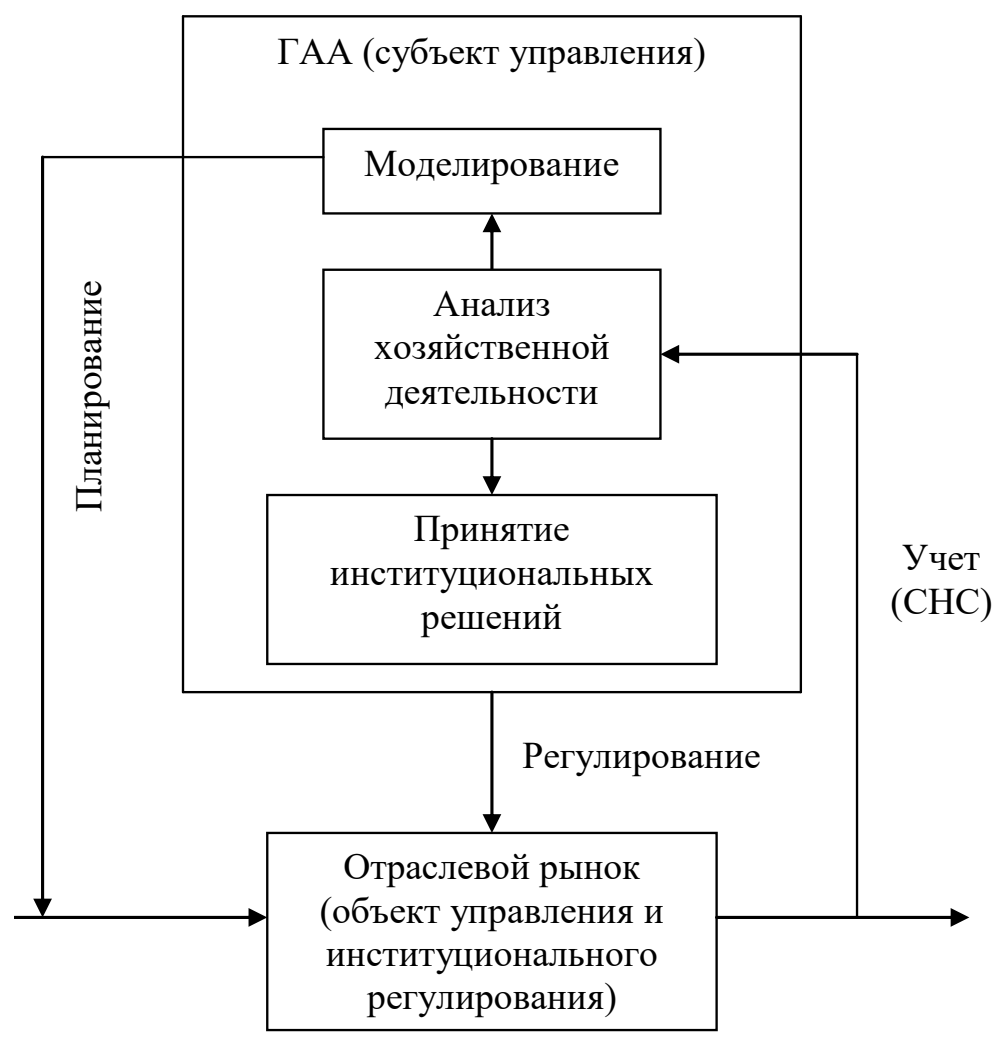

Рисунок 4. Государственно-административное (институциональное) управление развитием отраслевого рынка 
мере человеческого фактора. Этот недостаток пытались преодолеть представители школы человеческих отношений.

Здесь важно отметить, что, хотя властные прерогативы и полномочия определяются правовыми нормами и законодательными актами, осуществляются они вес же людьми [11]. От их воли, настроенности, знаний, опыта во многом зависит то, как осуществляются роли и функции, встроенные как в государственно-политическую систему в целом, так и в систему государственного регулирования отраслевых рынков.

Наиболее важна с этих позиций роль государства в определении «правил игры» между субъектами рыночных отношений. Речь в данном случае идёт о функции определения и обеспечения этих правил между субъектами рыночных отношений.

Важность данной функции определяется прежде всего тем, что в хозяйственной деятельности принимает участие большое число субъектов, имеющих различные экономические интересы. Поэтому весьма важно, чтобы государство приняло четко и ясно сформулированные и выполнимые законы и рамочные условия, регулирующие отношения как между производителями, так и между ними в целом и потребителями.

Исходя из отмеченного государство осуществляет контроль за хозяйственной деятельностью и, опираясь на законодательство, выполняет роль арбитра при разрешении проблем, возникающих между различными субъектами этой деятельности [3]. В случаях нарушения законо- дательства государство, естественно, вправе применить соответствующие санкции в отношении нечестных агентов рыночных отношений. Выполняя эту функцию, государство вводит правила поведения, которыми должны руководствоваться производители в своих отношениях с потребителями.

Первоначально большинство мероприятий в области государственного регулирования имело своей целью организацию рынка и защиту его функционирования [8]. Государственное вмешательство, как правило, ограничивалось разработкой и введением механизмов и процедур лицензирования, антимонопольных мер, регистрации корпораций и определенных параметров финансовой отчетности. Ныне роль государства сводится к созданию институтов, основополагающих правил и нормативов, необходимых для конкурентной среды.

ИРОР - это система мер законодательного, исполнительного и контролирующего характера, осуществляемых правомочными учреждениями и общественными организациями с целью придания процессам регулирования организованного характера, упорядочения действий и обеспечения соблюдения законов (с целью отстаивания своих интересов в терминах максимизации общественного благосостояния).

Общепринято выделение трёх способов ИРОР: законодательные, административные и судебные. При этом методы регулирования подразделяют на прямые и косвенные.

Кроме способов и методов в составе инсти-

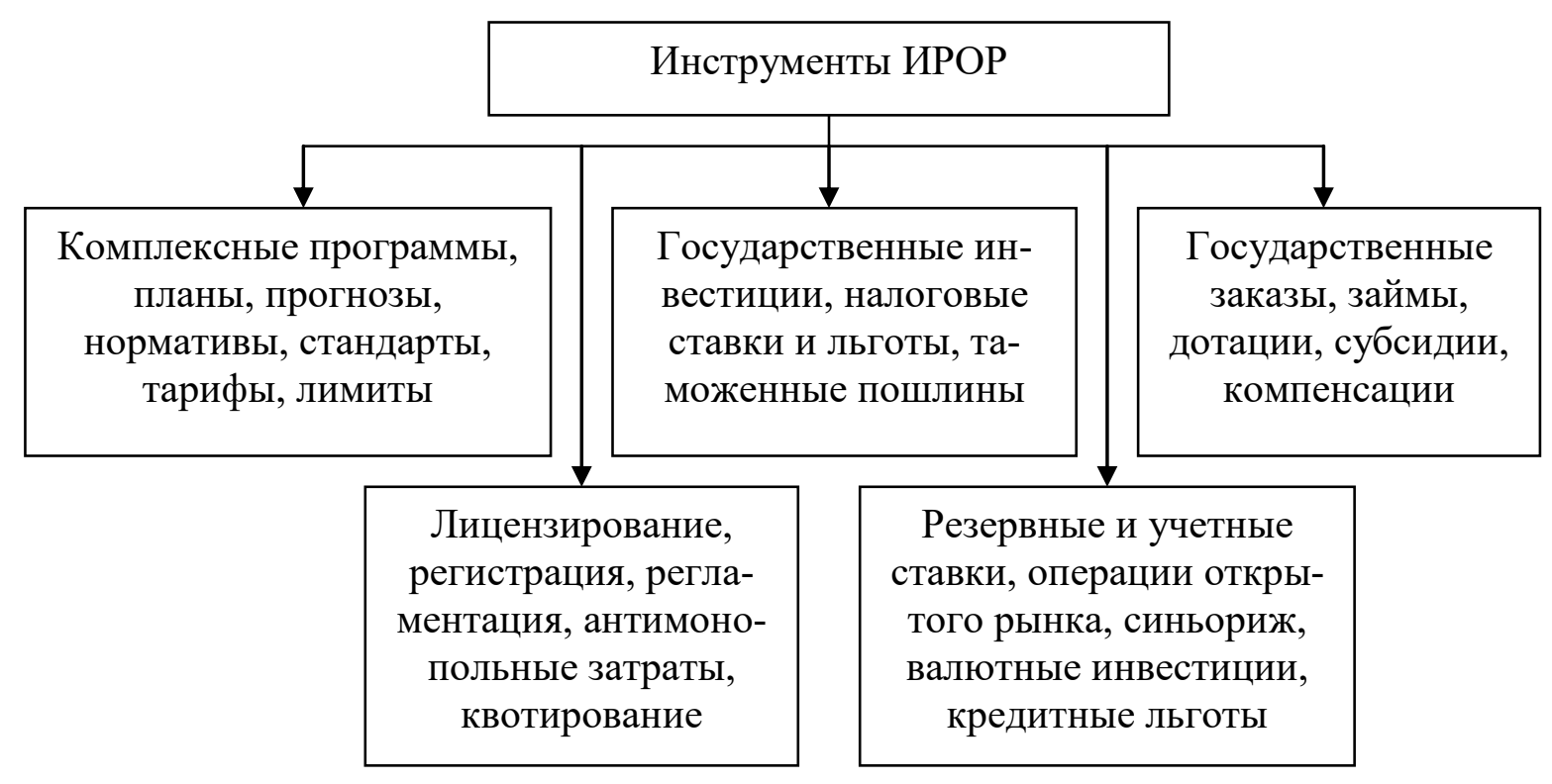

Рисунок 5. Инструменты институционального регулирования отраслевого рынка 
туционального механизма регулирования следует различать и его инструменты. Полный их перечень приведен на рисунке 5. Это комплексные программы, пошлины, налоговые ставки, индикативные нормативы и т.д.

Всеми этими инструментами ИРОР пользуются в своей деятельности различные органы управления адаптивной физической культурой. С их помощью они осуществляют экономическое регулирование, пользуясь не только прямыми, но и косвенными методами воздействия на величину трансакционных издержек физкультурно-адаптивной деятельности.

1. Рынок является составляющим элементом внешней среды для ФАО, будучи при этом достаточно сложной (и недостаточно структурированной - с позиций теории) системой.

2. Под рынком понимается институт, механизм сведения продавцов и покупателей (предъявителей спроса). Он характеризуется типом развития, методами оценки эффективности, модельным представлением и функциональными особенностями.

3. С позиций теоретических основ инновационного развития отраслевого рынка весьма значимыми являются: анализ факторов, определяющих его структуру; оценка уровня конкуренции; исследование барьеров входа на рынок организаций, производящих физкультурноадаптивные услуги.

4. Специфика структуры конкурентного отраслевого рынка является важным фактором разработки стратегической политики хозяйствующего субъекта сферы АФК, разработки его целей и задач инновационного развития.

5. Структура современного типа отраслевого рынка достаточно мобильна и характеризуется высокой степенью неопределенности. Поэтому рассматриваемые в работе вопросы инновационной направленности с учетом отраслевой специфики имеют исключительно важное значение.

\section{Библиографический список}

1. Государственное регулирование процессов развития региональных рынков / Под ред. А.Ф. Поповой.- Челябинск: УралГУФК, 2007.- 56 с.

2. Институциональная экономика / Под ред. Д. С. Львова.- М.: ИНФРА-М, 2001.- 318 с.

3. Крюков, Р.В. Государственное регулирование национальной экономики / Р.В. Крюков.- М.: Приор, 2005.$176 \mathrm{c.}$

4. Маршалл, А. Принципы экономической науки / А. Маршалл.- М: Дело, 1998. - 308 с.

5. Национальная экономика / Под ред. В.А. Шульги.-М.: Рос. экон. акад., 2000. - 529 с.

6. Новоселов, А.С. Теория региональных рынков / А.С. Новоселов.- Ростов-на-Дону: Феникс, 2002. - 448 с.

7. Попов, А.Н. Государственное регулирование национальной экономики / А.Н. Попов, А.Ф. Попова.- Челябинск: Институт экономики УралГАФК, 2003.- 44 с.

8. Райзберг, Б.А. Государственное управление экономическими и социальными процессами / Б.А. Райзберг.М.: ИНФРА-М, 2005.- 384 с.

9. Теория отраслевых рынков / Под ред. Е.Б. Колбачева и И.С. Штаповой. - Ростов н/Д.: Феникс, 2012. - 269 с.

10. Третьяк, В.П. Анализ отраслевой организации рынков / В.П. Третьяк // Экономист. - 2001.- № 1.-С. 11-16.

11. Щамхалов, Ф.И. Государство и экономика. Основы взаимодействия / Ф.И. Шамхалов.- М.: Экономика, 2000. - 382 c. 